\title{
Article \\ Geosynthetic Interface Friction at Low Normal Stress: Two Approaches with Increasing Shear Loading
}

\author{
Paolo Pavanello ${ }^{1, *(\mathbb{D}}$, Paolo Carrubba ${ }^{1}$ and Nicola Moraci ${ }^{2} \mathbb{C}$ \\ 1 ICEA Department, University of Padua, 35129 Padova, Italy; paolo.carrubba@unipd.it \\ 2 DICEAM, Mediterranea University of Reggio Calabria, 89122 Reggio Calabria, Italy; nicola.moraci@unirc.it \\ * Correspondence: paolo.pavanello@unipd.it
}

check for updates

Citation: Pavanello, P.; Carrubba, P.; Moraci, N. Geosynthetic Interface Friction at Low Normal Stress: Two Approaches with Increasing Shear Loading. Appl. Sci. 2022, 12, 1065. https://doi.org/10.3390/ app12031065

Academic Editor: Xiaowu Tang

Received: 22 November 2021

Accepted: 17 January 2022

Published: 20 January 2022

Publisher's Note: MDPI stays neutral with regard to jurisdictional claims in published maps and institutional affiliations.

Copyright: (C) 2022 by the authors. Licensee MDPI, Basel, Switzerland. This article is an open access article distributed under the terms and conditions of the Creative Commons Attribution (CC BY) license (https:// creativecommons.org/licenses/by/ $4.0 /)$.
Featured Application: An insight into the possible influence of the nonuniform normal stress distribution in the inclined plane test, by comparing the results with an unconventional direct shear device, working with increasing shear load rather than controlled displacement.

\begin{abstract}
The evaluation of geosynthetic interface friction is a key parameter for the stability of coupled geosynthetics, as in landfill capping liner. At the present time, few types of tests are suitable for measuring the interface friction at low normal stress: one of these is the inclined plane, usually carried out under a vertical stress of $5 \mathrm{kPa}$. This type of test is not without critical aspects, mainly due to the nonuniform normal stress state induced by the inclination of the plane, but, on the other hand, the most widespread direct shear test generally cannot be performed at such low values of normal stress. After a short discussion on the pros and cons of these two types of test, the paper presents a comparison of the interface friction angles obtained, for three interfaces, by means of an inclined plane and an unconventional direct shear apparatus, under the same low normal stress. The peculiarity of this latter device is of ensuring a gradual increase of the mobilized strength, in a way similar to what occurs during the inclined plane test. The good correspondence of the results of the two types of tests confirmed the validity of both the test approaches.
\end{abstract}

Keywords: geosynthetic; interface friction; inclined plane; direct shear; geomembrane; drainage geocomposite; geogrid

\section{Introduction}

Starting from the evidence of the undoubted advantages that the use of geosynthetics entails in geotechnical works, a continuous improvement of the knowledge on the short and long-term behavior of these polymeric materials could be desirable, in order to use these products knowledgably. In this context, an adequate expertise of the friction that these materials can mobilize when placed in contact with each other is necessary, since it is a common practice to combine layers of geosynthetics, having different functions, thus forming multilayer packages. Consequently, each contact surface between two geosynthetics, as well as those between geosynthetic and soil, represent a potential critical element for the stability, given the modest friction values that these surfaces generally can mobilize. This aspect assumes considerable relevance in the design phase and can be a source of serious errors if not properly addressed, even because a correct characterization of the interface friction is not so simple, having to take into account also the peculiarities of the behavior of the polymeric materials.

With reference to the evaluation of the static interface friction, several types of laboratory tests have been developed over the years [1,2] such as the direct shear test, the inclined plane test [3-6], the annular shear test [7,8] and the cylindrical shear test [9].

However, few types of tests are suitable for evaluating the interface friction at very low normal stress: one of these is the inclined plane test, usually carried out under a 
vertical stress of $5 \mathrm{kPa}$. This type of test, although not without critical aspects, represents an interesting tool for investigating the behavior of interfaces. For this reason, a short discussion on the main differences between the inclined plane and the direct shear tests will be first introduced, in order to highlight the advantages and disadvantages of each methodology. Later, a comparison of the results obtained with the inclined plane and a nonstandard horizontal shear device will be proposed. This latter device allows performing horizontal shear test at the same vertical stress of the inclined plane and it is characterized by a sliding force gradually increasing over time.

\section{The Direct Shear and the Inclined Plane Tests: Pros and Cons}

The direct shear is probably the most known and widespread methodology of test for studying the interface friction. It is standardized by the ASTM D 5321-8 [10] and by the EN ISO 12957-1 [11] and it is carried out on specimens having minimum size of $300 \mathrm{~mm} \times 300 \mathrm{~mm}$, arranged horizontally and fixed to two supports, one of which remains still during the test while the other can slide with respect to the first. Once a prefixed normal stress is applied, half the device is pushed at a constant speed of $1 \pm 0.2 \mathrm{~mm} / \mathrm{min}$ while the contrast force necessary to keep firm the other half of the device is measured, until a maximum displacement of $50 \mathrm{~mm}$ is reached. In order to identify the failure envelope, the tests are repeated for at least three different values of normal pressure (i.e., for the European standard $50 \mathrm{kPa}, 100 \mathrm{kPa}$ and $150 \mathrm{kPa}$ ), and subsequently the envelope friction parameters $\left(c^{\prime}, \varphi\right)$ are evaluated by linear interpolation of the results.

On the other hand, the inclined plane test is standardized only by the European EN ISO 12957-2 [12] and it should be noted that, strictly speaking, this rule refers only to interfaces between soil and geosynthetics, even if its indications can be easily extended also to the case of contact between geosynthetic and geosynthetic. The equipment used for this type of test consists of a tiltable plane, above which a steel block is placed. This element is able to slide along the plane and its motion can be directed by lateral guides or by vertical carriages, acting outside the contact area of the geosynthetics. The first geosynthetic, of the examined interface, is fixed on the inclined plane while the second is bound to the bottom of the upper block; in analogy with the direct shear test, the specimens should have a minimum size of $300 \mathrm{~mm} \times 300 \mathrm{~mm}$. The test starts with the plane in the horizontal position and, gradually, the inclination of the plane is increased, at a constant speed of $3 \pm 0.5^{\circ} / \mathrm{min}$. During the test, the relative displacement of the upper block respect to the plane is monitored and the inclination angle of the plane, for which the sliding of the block occurs, is researched. According to the EN ISO 12957-2, the interface friction angle $\varphi$ is equal to the plane inclination angle $\beta$ reached when the upper block showed a reference displacement of $50 \mathrm{~mm}$ :

$$
\tan \varphi=\tan \beta_{50 \mathrm{~mm}}
$$

Referring to this assumption, it is important to note that the displacement value of $50 \mathrm{~mm}$, taken in analogy with the direct shear test, is actually an arbitrary reference; to remember that this friction angle is evaluated according to the standard EN ISO 12957-2, in the following, it will be denoted as "standard friction angle" $\left(\varphi_{\text {stand }}\right)$. Moreover, we should point out that Equation (1) is correct only in the hypothesis that the block is in a static equilibrium, while its condition is more properly kinematic, given that it is in motion with speed and acceleration that are not always negligible [13]. For these reasons, some attempts to improve the inclined plane procedure are still in progress [14], as well as to research alternative procedures $[15,16]$.

On the differences between the two methodologies, it should first be noted that the direct shear test is carried out at three different values of normal stress, in order to delineate the failure envelope, while the inclined plane test is conducted at a single value of normal stress and consequently it is interpreted in terms of secant friction angle, rather than the tangential one.

This is not the only difference: for example, the range of normal stress, usually investigated, is higher for the direct shear test. The common laboratory shear devices allow 
perform tests under normal stress varying between extreme values of about $25 \mathrm{kPa}$ and $500 \mathrm{kPa}$. Conversely, it is difficult to manage very low normal stress, because to the way in which the normal load is applied, that is through a hydraulic press. On the other hand, the inclined plane test is carried out only under very low normal stresses, generally equal to $5 \mathrm{kPa}$, which can be eventually increased to slightly higher values, up to about 10-15 kPa.

This difference of the investigated range of normal stress makes difficult the comparison of the results obtainable with the two types of tests, the direct shear and the inclined plane, and consequently the evaluation of the equivalence of the two approaches. However, the results reported in some studies $[17,18]$ seem to indicate that the extrapolation of the results of direct shear tests to the field of low normal stresses may overestimate the interface shear strength with respect to the strength parameters provided by inclined plane tests. In this regard, it should be pointed out that the failure envelope of the interfaces between geosynthetics can be curvilinear and, therefore, the choice of the type of laboratory tests should be related to the actual stress condition to which the interface is subjected on site. For example, using the results of direct shear tests, performed as said at medium-high stresses, for the design of the capping of a landfill, condition characterized by low vertical stress, may be very little precautionary. Similarly, the opposite case of the extension of the inclined plane test results to the design of lateral liners, where the geosynthetics are subjected to high normal stresses, could be unsafe.

In addition to the different stress range, another possible reason for differences between the results provided by the two types of test may be the different way of application of the shear stress. Indeed, in the case of direct shear, the interface experiences an imposed displacement at constant speed of $1 \mathrm{~mm} / \mathrm{min}$, while the response is evaluated in terms of shear force. On the contrary, in the inclined plane the interface is subjected to a gradually increasing shear stress, given by the component of the weight parallel to the plane, which increases as the plane inclination increases, and the interface response is detected in terms of block displacement. In summary, in the first case a displacement is imposed and the shear force is detected while in the second case a shear force is imposed and the displacement is detected. Although few studies on this subject are currently available [19], it can be stated that the approach followed in the inclined plane test is much more similar to the real kinematics involved by the sliding of an interface placed on a slope. Moreover, the findings of recent research seem to suggest that the direct shear approach could overestimate the friction when the interface can manifest very slow sliding phenomena, at speeds lower than that usually imposed in the direct shear test [14].

Continuing the discussion, another aspect to consider is the maximum displacement, allowed by the two devices, that is generally noticeably different. In the case of the direct shear, the standard requires a displacement of $50 \mathrm{~mm}$ and, in general, the maximum stroke of the devices is slightly higher than this value. This level of displacement may be insufficient to detect the residual shear resistance [8], but the only way to study the shear strength at large displacements with these devices is to perform many cycles of displacement, with motion reversal. However, this approach does not exactly correspond to the physics of the real phenomenon, since it involves a reordering of the geosynthetic fibers, or a different action on the microscopic asperities, at each inversion of the motion direction. This problem does not arise in the case of inclined plane tests, in which the maximum interface displacement can be several tens of centimeters, depending only on the length of the plane over which the block slides. In this case, the maximum displacement can be further increased by realizing several slips in succession, while being careful to bring back the block to its initial position and lifting it so as not to rub the material.

Another aspect to take into account is the hydration state of the interface implementable in the two types of test. For the direct shear, the test condition can range from dry to completely immersed, while for the inclined plane only dry and damp conditions can be executed, but not the immersed condition, unless the device is placed in a tank, a solution that is in fact quite not practicable, or unless a seepage motion is introduced at the interface [20]. 
To complete the discussion of the advantages and disadvantages of the two types of tests, it is necessary to remember that a common issue of the inclined plane test is related to the nonuniform distribution of the normal stress on the contact surface when the plane is inclined [21]. Indeed, if the normal stress could be considered uniform when the plane is horizontal, due to the eight of the center of mass respect to the base of the block, the distribution varies with the inclination of the plane, becoming trapezoidal, with higher stress values on the downstream edge and lower on the upstream one. To limit this effect, the EN-ISO 12957-2 recommends the use of some precautions such as the adoption of inclined side walls or the use of wedges, to obtain a backward position of the center of mass. In this way the normal stress distribution becomes nonuniform when the plane is horizontal but reaches a uniform condition at a certain prefixed inclination of the plane.

As seen, the different devices present each some pros and some cons; in this work a different experimental apparatus is presented, designed to study the interface friction between geosynthetics at low normal stresses, overcoming some limitations of the inclined plane device. This apparatus combines the typical advantages of the inclined plane, like the ability of performing tests under a condition of shear force increase, with the possibility of performing tests without eccentricity of the normal load and also in immersed condition. Lastly, the results obtained for three different interfaces will be presented and compared with those provided by the usual inclined plane tests.

\section{Devices}

In this work, two different devices were adopted. The first device was an inclined plane apparatus (Figure 1), characterized by a plane with a length of $1.10 \mathrm{~m}$ and width of $0.25 \mathrm{~m}$ and a steel block with a contact base of $0.21 \mathrm{~m} \times 0.42 \mathrm{~m}$.
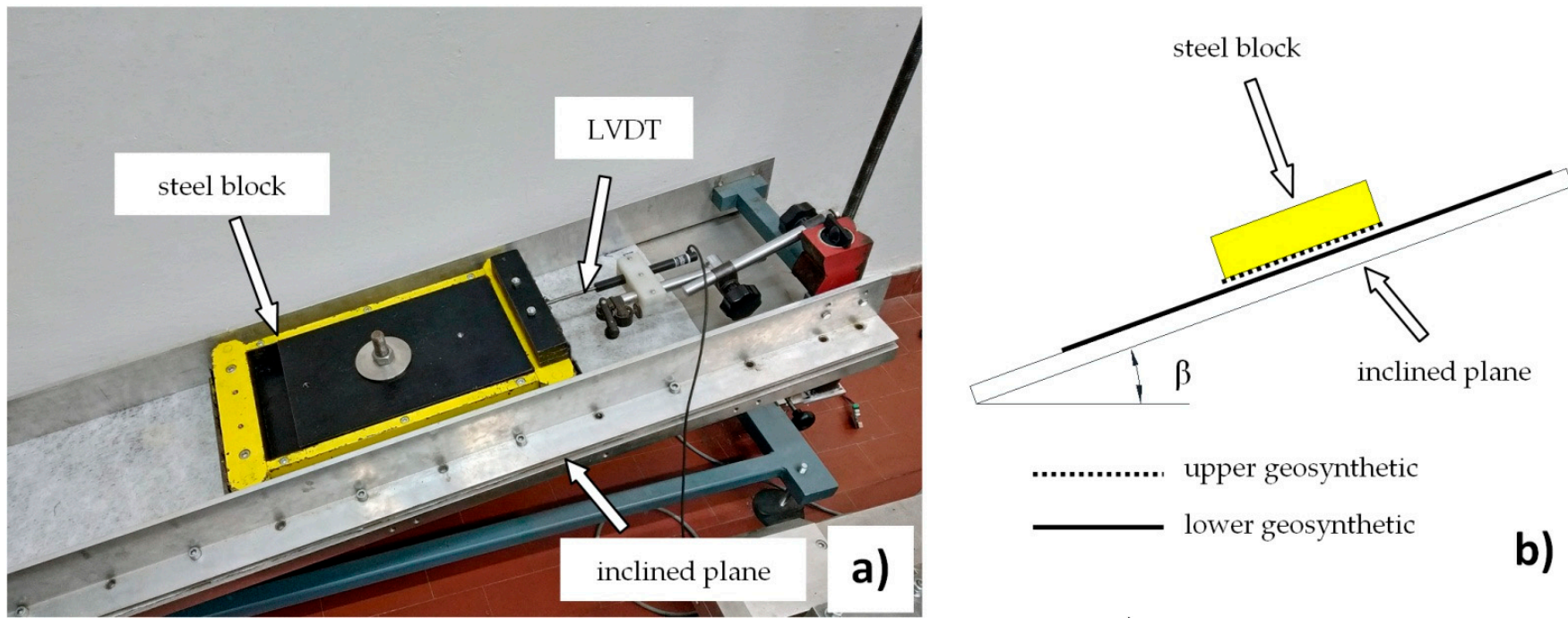

Figure 1. The inclined plane device: (a) side view and (b) sketch.

The first geosynthetic specimen was fixed to the base of the block, while the second was fixed on the plane. In order to ensure a straight sliding, the block was constrained by two lateral guides and it was equipped with four lateral wheels, to avoid introducing significant additional friction forces. The inclination of the plane was measured by means of an accelerometer, while the block displacement was detected with a Linear Variable Displacement Transducer (LVDT). For the block, a rectangular shape was adopted, instead of the standard measures of $0.30 \mathrm{~m} \times 0.30 \mathrm{~m}$, to minimize the effects of the normal load eccentricity, while maintaining the same contact area of $0.09 \mathrm{~m}^{2}$. In this regard, in the device setup adopted in this research, the height of the center of gravity of the block, for a mean normal stress of $5 \mathrm{kPa}$, was of only $34 \mathrm{~mm}$ and the center of mass was backward of about $12 \mathrm{~mm}$. This configuration allowed to be obtained a uniform distribution of the normal 
stresses for an inclination angle of $21^{\circ}$, reputed to be an acceptable compromise between the maximum and minimum values of interface friction observed during the tests.

The second device was a not standard apparatus, similar to a direct shear except for the way the shear stress was applied. It was composed of a steel block, with dimensions of $0.30 \mathrm{~m} \times 0.30 \mathrm{~m}$, resting on a horizontal plane. Also in this case, the first geosynthetic specimen was fixed to the base of the block, while the second was fixed on the plane. The block was hooked, with the interposition of a load cell, to a steel cable at the end of which, after a series of pulley, a counterweight was attached (Figure 2). The test was carried out by gradually varying the shear force over time by means of a simple mechanism based on a hopper, through which some sand drops smoothly into a bucket (the counterweight) and ended when the block displacement reached the values of $50 \mathrm{~mm}$.
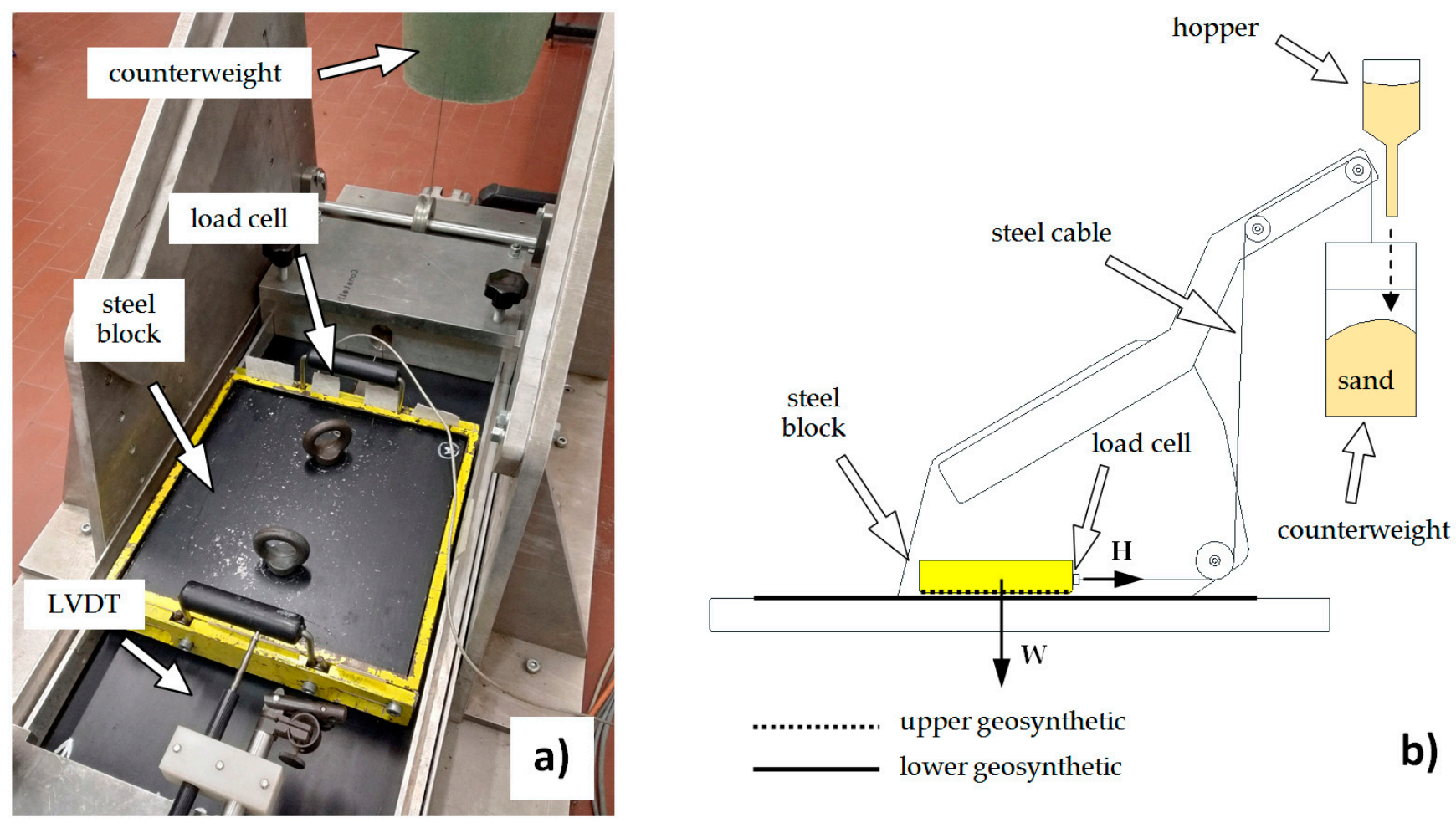

Figure 2. The direct shear apparatus: (a) view from the top and (b) sketch.

During the test, the horizontal force applied to the block was detected by the load cell while the block displacement was measured by a LVDT. Starting from the hypothesis of a static condition, the measurement of the horizontal force applied $(\mathrm{H})$, related to the weight of the block (W), makes possible the evaluation of the mobilized friction angle, time by time, by means of the following simple equation:

$$
\tan \varphi=\frac{\mathrm{H}}{\mathrm{W}}
$$

Once the limit static equilibrium is reached, Equation (2) would no longer be valid, but, in analogy with what is normally done for the inclined plane test, it was extended to the whole test, even if the speed and acceleration of the block were not actually negligible.

To remark the difference with the usual direct shear, in the following this type of test will be indicated as SSI test, where the acronym indicates that the experiment was carried out following a shear stress increase.

\section{Studied Interfaces}

Three interfaces were studied, by coupling various geosynthetics; a first interface was represented by the contact between a structured HDPE geomembrane (GMB) and a 
drainage geocomposite $\left(\mathrm{GCD}_{1}\right)$. The geomembrane had thickness of $1.5 \mathrm{~mm}$, mass per unit area of $1.42 \mathrm{~kg} / \mathrm{m}^{2}$ and tensile strength of $22.5 \mathrm{kN} / \mathrm{m}$. The drainage geocomposite was formed by a draining body enclosed between two nonwoven geotextiles, made of polypropylene; it had a thickness of $5.5 \mathrm{~mm}$ under a pressure of $2 \mathrm{kPa}$, mass per unit area of $0.90 \mathrm{~kg} / \mathrm{m}^{2}$ and tensile strength (equal for MD and CMD) of $20 \mathrm{kN} / \mathrm{m}$.

The second interface was the contact between two specimens of a same woven geotextile $\left(\mathrm{GTX}_{\mathrm{w}}\right)$, made of polypropylene, having mass per unit area of $400 \mathrm{~g} / \mathrm{m}^{2}$ and tensile strength (MD) of $90 \mathrm{kN} / \mathrm{m}$.

The contact between another drainage geocomposite $\left(\mathrm{GCD}_{2}\right)$ and a geogrid (GGR), without the presence of the soil, was the third interface examined.

Referring to the testing conditions, all tests were carried out at a laboratory temperature of $22 \pm 3^{\circ} \mathrm{C}$ and under a normal stress of $5 \mathrm{kPa}$. All the interfaces were studied in the dry condition apart from the first and third interfaces that were studied, for comparative purposes, also in the wet condition. In this case, the specimens were fully immersed in water before the test but, while in the direct shear device they remained immersed in water throughout the test, in the inclined plane device they were only partially saturated, because the water naturally drained away due to the inclination of the plane.

Finally, to achieve a consistent number of data, which would allow to compare the different devices and conditions, the tests were repeated several times, as summarized in Table 1.

Table 1. Summary of the number of tests carried out for each interface.

\begin{tabular}{cccc}
\hline Interface & $\begin{array}{c}\text { Tested } \\
\text { Conditions }\end{array}$ & $\begin{array}{c}\text { Number of Inclined } \\
\text { Plane Test }\end{array}$ & $\begin{array}{c}\text { Number of Direct } \\
\text { Shear SSI Test }\end{array}$ \\
\hline GMB-GCD $_{1}$ & dry/wet & 54 & 34 \\
GTXw $_{w}-G T X_{w}$ & dry & 22 & 16 \\
GCD $_{2}-G G R$ & dry/wet & 35 & 41 \\
\hline
\end{tabular}

\section{Test Results}

Referring to the first interface, GMB-GCD 1 , Figure 3, shows a typical result of an inclined plane test, on dry virgin specimens, in terms of displacement of the block as a function of the plane inclination. Remembering that, in this type of test, the interpretation is performed according to Equation (1), by assuming always a static condition for the block, the angle of plane inclination is also equal to the mobilized friction angle.

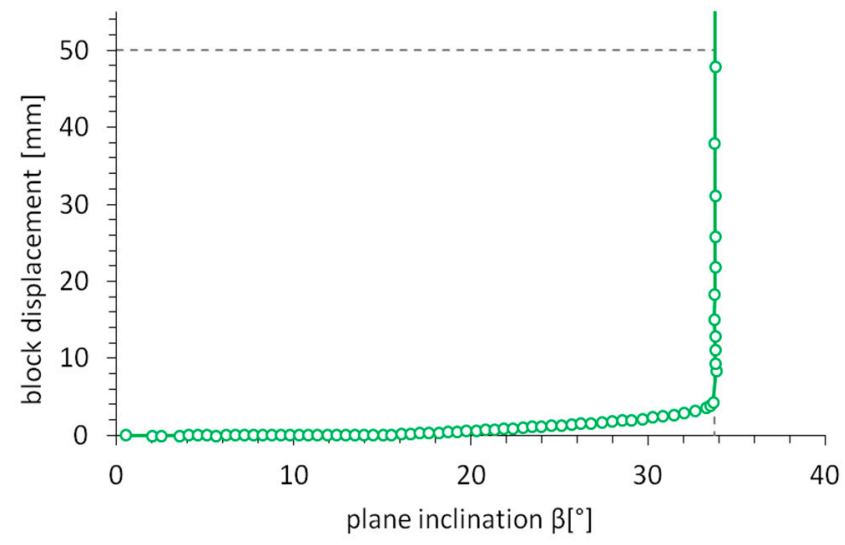

Figure 3. Results of an inclined plane test on the GMB-GCD 1 interface.

Conversely, Figure 4 shows an example of a direct shear SSI test, on the same interface and on dry virgin specimens; in detail, Figure 4a shows the increasing horizontal force and the corresponding block displacement versus the time, while Figure $4 \mathrm{~b}$ shows the mobilized friction angle and the block speed as a function of the block displacement. In analogy with 
what is usually done in the case of the inclined plane test, also in this case the interpretation of the results was made assuming a static equilibrium of the block (Equation (2)), even if the block speed and acceleration were not actually negligible. It is interesting to observe that, virtually flipping the axes of Figure 3, the evolution of the mobilized friction respect to the block displacement is similar to the curve of Figure $4 \mathrm{~b}$.
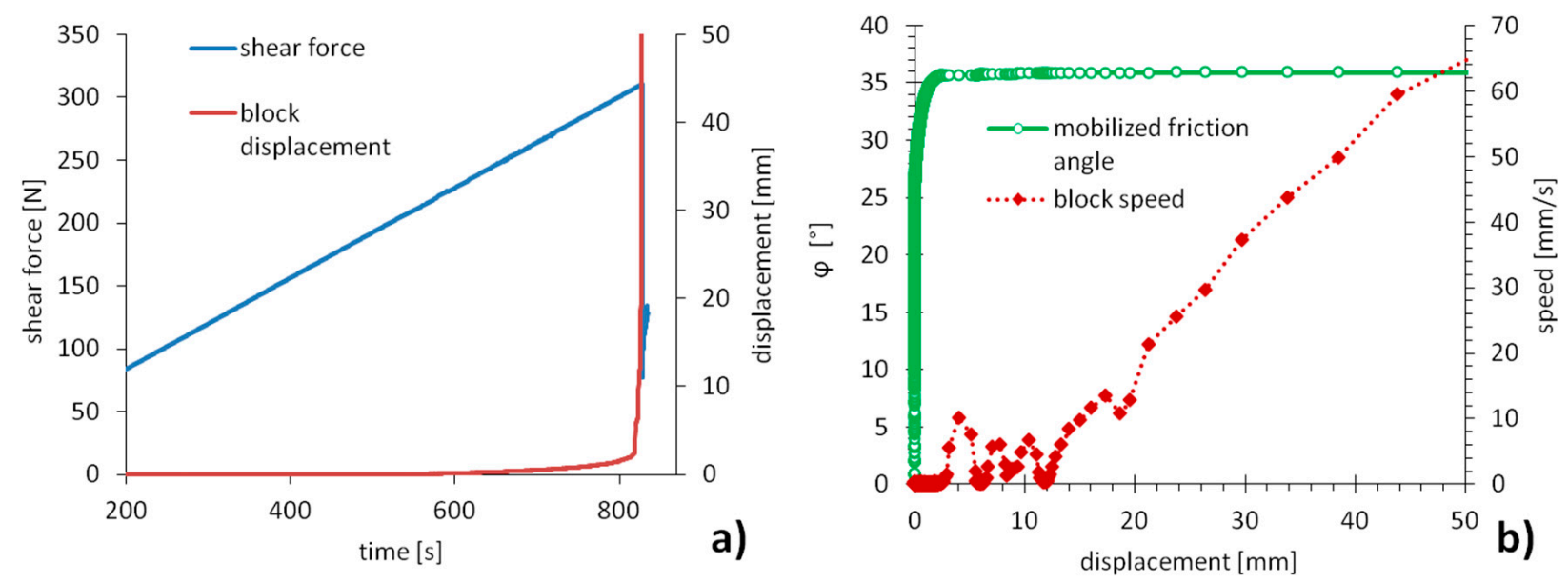

Figure 4. Results of a direct shear (SSI) test on the GMB-GCD 1 interface: (a) shear force and block displacement versus time and (b) mobilized friction angle and block speed versus displacement.

Following an approach already presented in other research [22,23], after the first evaluation, carried out on virgin specimens, the tests were repeated several times, repositioning the block, after each sliding, in the initial position and proceeding in the same way for both the inclined plane and the direct shear SSI tests. Numerous values of the friction angle were thus obtained, related to the amount of the cumulated displacement experienced by the interface, which was pushed up to approximately $1.6 \mathrm{~m}$, thus allowing us to investigate the wear effect [24]. Three pairs of specimens were studied, for each device, in the dry condition; moreover, the tests were repeated in the wet condition on three different pairs of specimens, for the inclined plane, and three others for the direct shear, for a total of 12 pairs of specimens and about 72 tests achieved. A comparison of the results, for the two conditions and for the two types of tests, is showed in Figure 5a, for the dry condition, and in Figure 5b, for the wet condition, in terms of standard friction angle versus cumulated displacement. The data show a good agreement between the two types of tests and a similar trend of the interface friction with the cumulated displacement is highlighted by both the methodologies, corresponding to a moderate reduction of the available friction with the increase of the wear.

Albeit theoretically the nonuniformity of the normal stress could change the measured mobilized friction, giving rise to phenomena of progressive failure, in the literature there are not many experimental data on this topic. Consequently, the tests in dry condition were repeated, on another set of three pairs of specimens, with a different mass distribution of the sliding block, to analyze the possible influence of the normal load eccentricity. A uniform distribution of mass, inside the block, was adopted, instead of the configuration with the center of mass positioned backward and previously described.

At a reference inclination of $28^{\circ}$, equal to the mean value of the friction for this interface, the uniform mass distribution ("configuration 2") involved a variation of the normal stress of $\pm 25 \%$ respect to the mean value, while the configuration with the center of mass positioned backward ("configuration 1") entailed a variation of only $\pm 6 \%$. The comparison of the results is proposed in Figure 6 and, as can be observed, the different distribution of the masses did not induce significant differences in the results, considering the normal data scattering. 


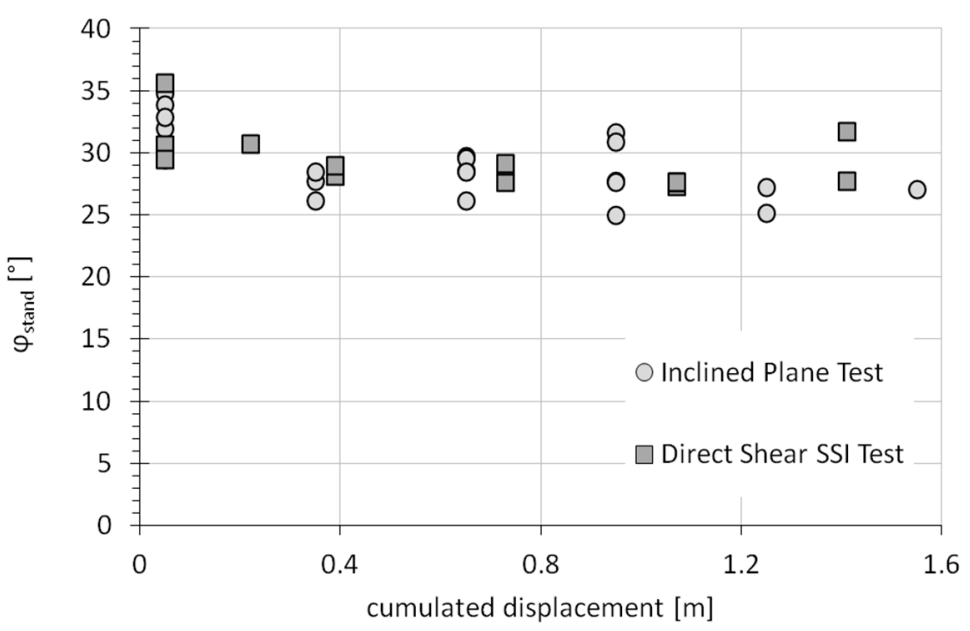

a)

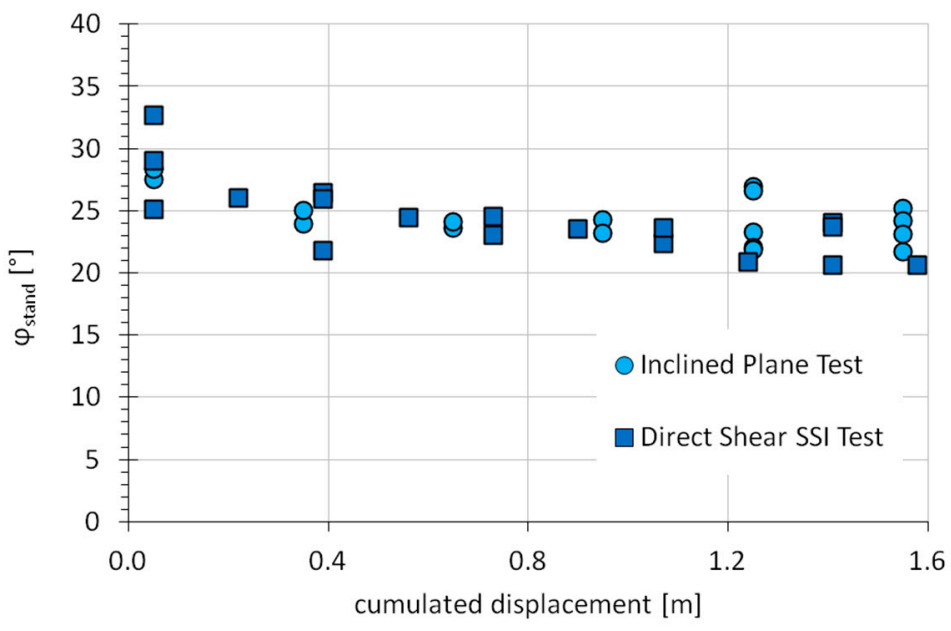

b)

Figure 5. Summary of results for the GMB-GCD 1 interface: (a) dry and (b) wet conditions.

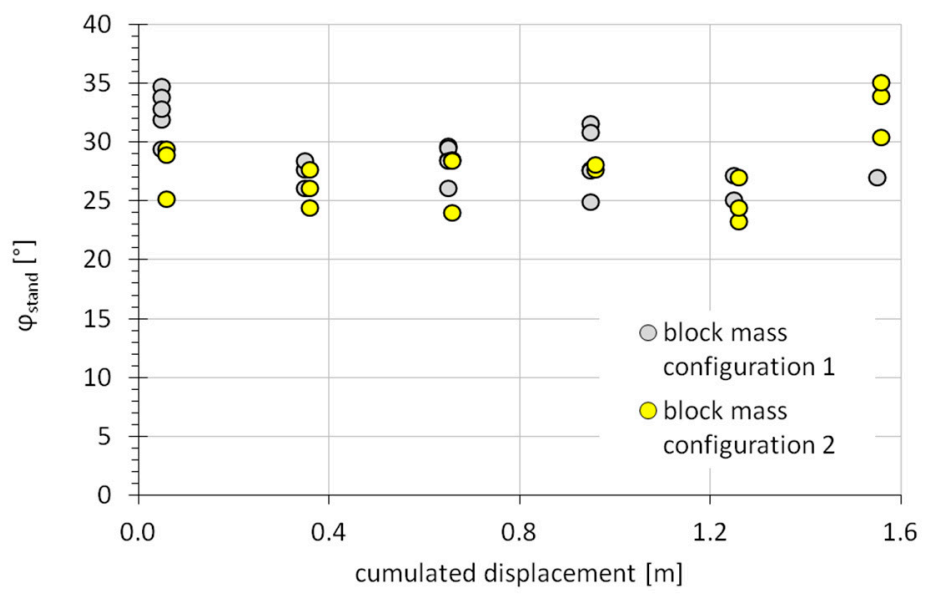

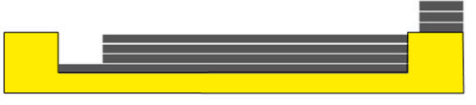

block mass configuration 1

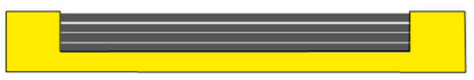

block mass configuration 2

Figure 6. Results of inclined plane tests, for the GMB-GCD 1 interface, for two different mass configurations of the sliding block.

An example of the results obtained for the second examined interface, GTXw-GTXw, is shown in Figure 7; in detail Figure 7a shows the results of an inclined plane test on dry virgin specimens, in terms of displacement of the block versus the plane inclination, while Figure $7 \mathrm{~b}$ shows the results of a direct shear SSI test, again on dry virgin specimens, in terms of mobilized friction angle and block speed versus the interface displacement. Even in this case, the figures show a similar behavior of the interface, in terms of evolution of the mobilized friction respect to the block displacement, in the two types of tests. This 
interface was characterized by a "sudden sliding" behavior [14], with an abrupt increase of the block speed at the reaching of the limit static equilibrium. For this interface the tests were repeated many times on various pairs of specimens, for a total of 22 tests on the incline plane and 16 direct shear SSI tests. A graphical summary of the results provided by the two devices, in function of the cumulated displacement or, in other terms, of the wearing level, is reported in Figure 8. As can be seen, the two methodologies show a very good correspondence of their results, in terms of both average value and data scattering. Referring to the wear effect, unlike the previous case, this interface exhibited a slight increase of the friction as the cumulated displacement increased.
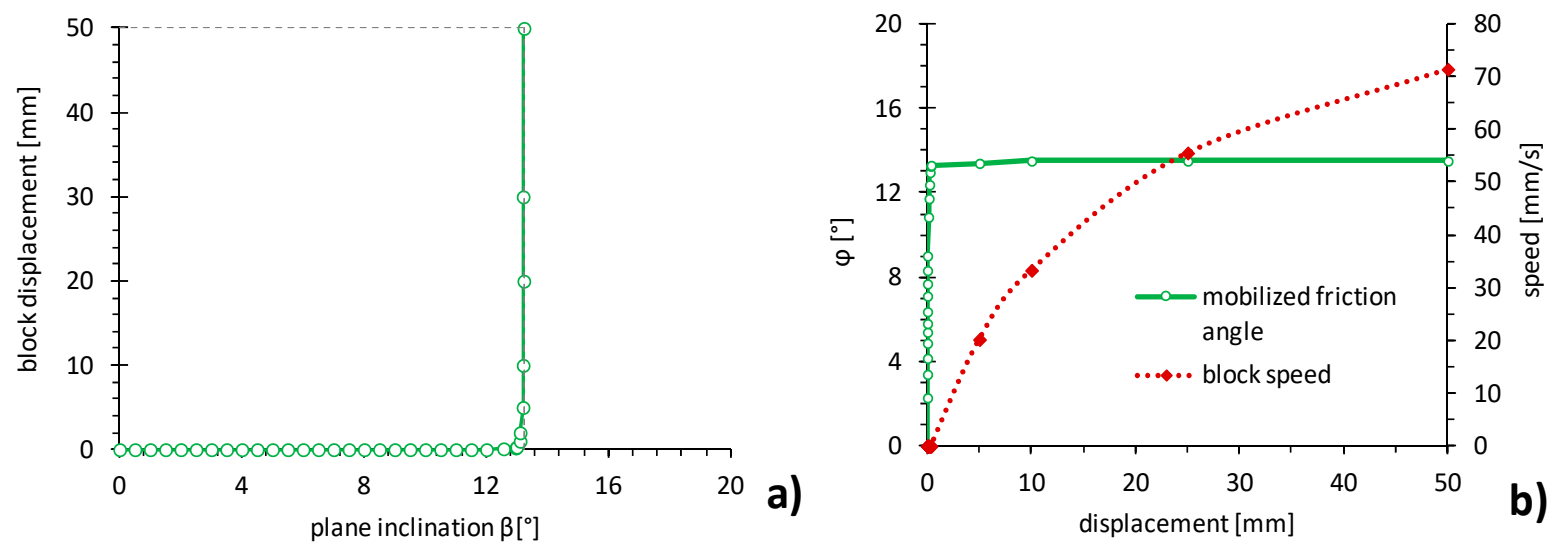

Figure 7. Typical results for the GTXw-GTXw interface: (a) inclined plane test and (b) direct shear SSI test.

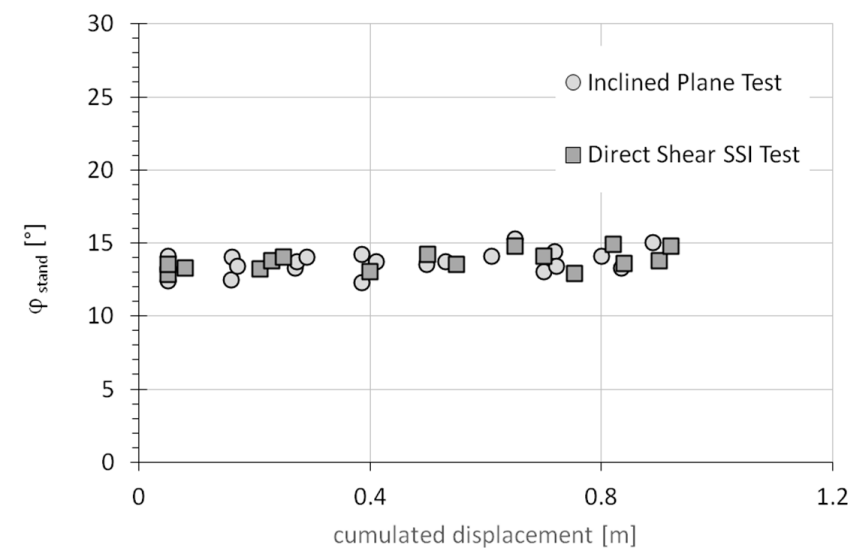

Figure 8. Summary of results for the GTX ${ }_{w}-G T X_{w}$ interface in the dry condition.

The third considered interface, $\mathrm{GCD}_{2}$-GGR, is an example of contact characterized by a "gradual sliding" behavior [14], as can be deduced observing the results of an inclined plane test (Figure 9a) or those of a direct shear SSI test (Figure 9b), in both cases carried out on dry virgin specimens. The main feature of the "gradual sliding" behavior is that a relatively slow motion occurs at reaching the limit static equilibrium and that very slow displacements can occur also at mobilized friction angles significantly lower than the standard friction angle.

A graphical summary of the result set is provided by Figure 10a, for the dry condition, and by Figure 10b for the wet condition. A total of 76 tests were conducted for this interface (35 inclined plane tests and 41 direct shear SSI tests). In this case the two methodologies show a good correspondence of results, with a limited difference for the data related to the wet condition. Regarding this last aspect, it should be noted that the wet condition is not exactly the same in the inclined plane and in the direct shear device. Indeed, in the inclined plane test, the water naturally drains away from the specimens, due to the 
increasing inclination of the tilting plane, while in the direct shear device the specimens remain immersed in water throughout the test. This operational diversity may explain the difference of the results obtained in wet condition. As a final note, Figure $9 a, b$ show in both cases a noticeable reduction of friction as the cumulated displacement increases, in dry as well as in wet conditions.
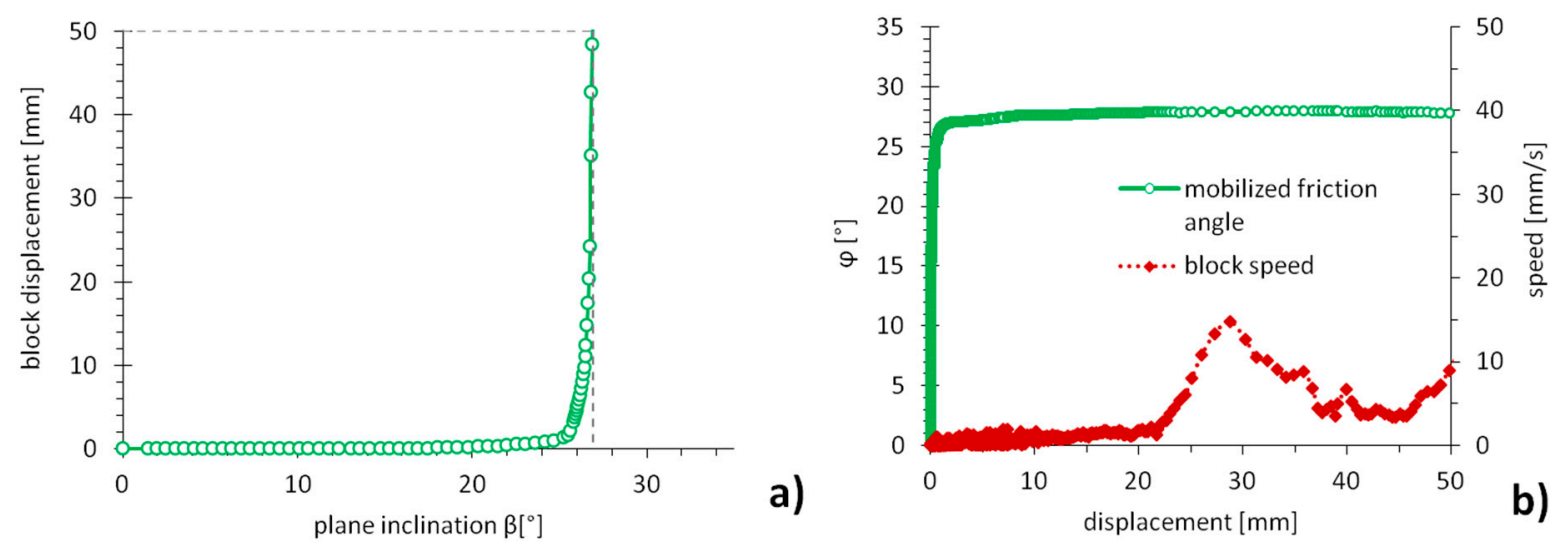

Figure 9. Typical results for the $\mathrm{GCD}_{2}$-GGR interface: (a) inclined plane test and (b) direct shear SSI test.

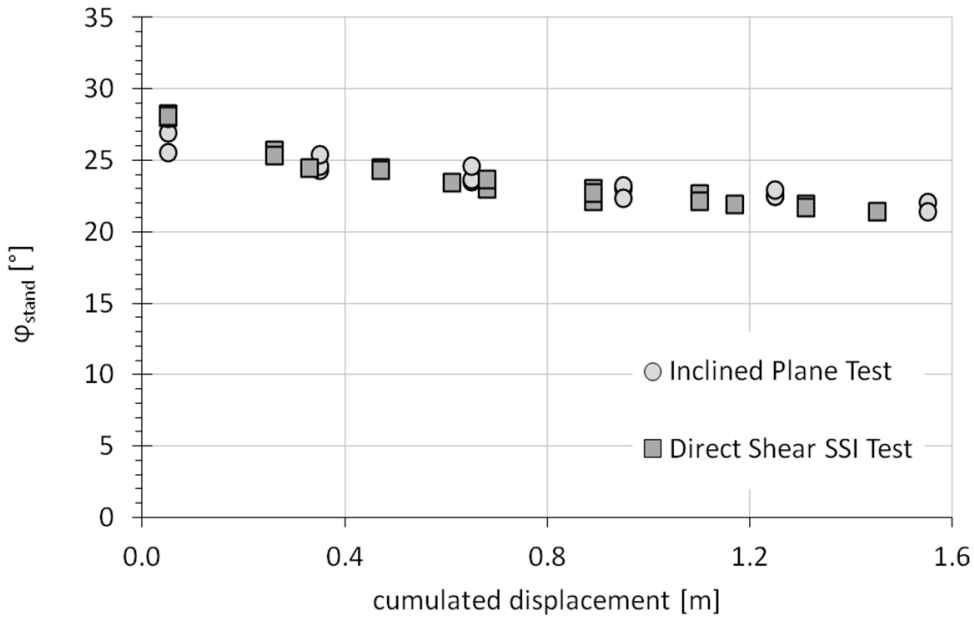

a)

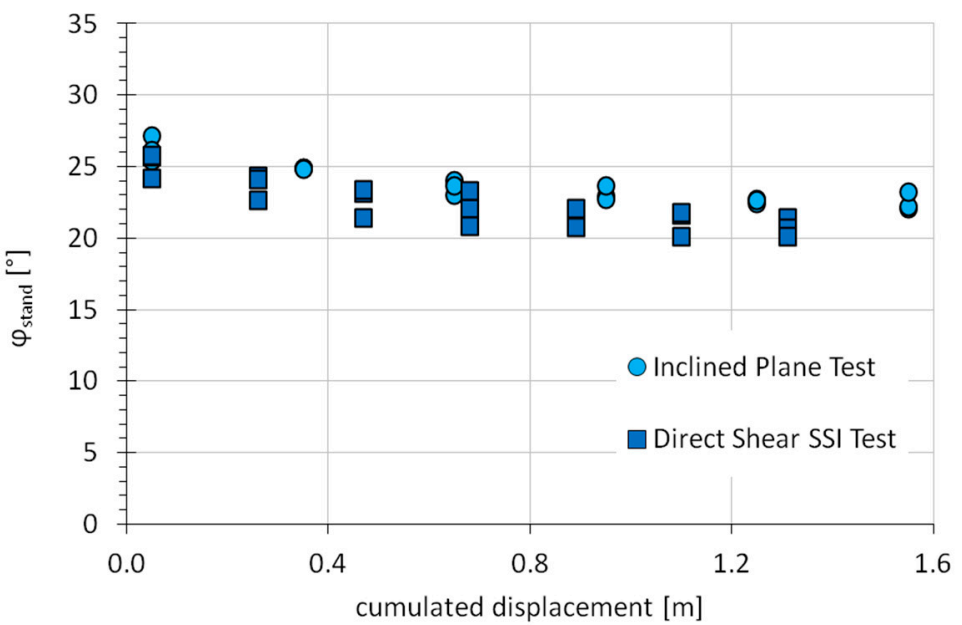

b)

Figure 10. Summary of results for the $\mathrm{GCD}_{2}$-GGR interface: (a) dry and (b) wet conditions. 


\section{Conclusions}

In this paper, a comparison between the results of inclined plane tests and those obtained by means of a different experimental apparatus, have been presented. The latter device is capable of performing horizontal shear tests, at a vertical stress as low as $5 \mathrm{kPa}$, by ensuring a gradual increase of the mobilized strength, in a way similar to what occurs during the inclined plane test.

The experimental data showed a good correspondence between the results obtained with the two devices. This allows some conclusions to be drawn. The first is that the nonuniformity of the normal stress, an intrinsic factor of the inclined plane test, does not involve significant changes in the results, if compared to the centered load condition of the direct shear test. This conclusion is valid at least for the adopted block, with a rectangular area of contact and a low center of gravity, and for the moderate angles of inclination achieved during the tests. From this point of view, these tests exclude one of the main objections that could be made against the inclined plane approach.

Another observation is that the data show that the same evolution of friction with respect to the wear is outlined by the two apparatuses, even if the maximum displacement achievable in a direct shear test is less than that of the inclined plane test, and therefore a greater number of repetitions of direct shear tests are required to get to the same displacement level.

Lastly, the direct shear SSI test constitutes a valid alternative to the inclined plane test for the measurement of the interface shear strength between geosynthetics at low normal stress values. In addition to the absence of eccentricity of the normal load, it has the advantage of allowing the test of specimens in immersed condition, which is not possible with the inclined plane apparatus. The main point of interest is that this type of device allows a gradual increase of the shear stress, leaving free the interface response in terms of displacement, unlike the conventional approach of the direct shear test, in which the interface displacement is imposed over time. The few studies available on this subject seem to indicate that the method of application of the load may have a certain influence on the response of the interface, or rather on the measured friction angle. For these reasons, further studies, considering the comparison between tests carried out with imposed displacement or with imposed shear load, are desirable.

Author Contributions: Conceptualization, P.P., P.C. and N.M.; methodology, P.P.; data curation, P.P.; writing - original draft preparation, review and editing, P.P.; supervision, P.C. and N.M. All authors have read and agreed to the published version of the manuscript.

Funding: This research received no external funding.

Conflicts of Interest: The authors declare no conflict of interest.

\section{References}

1. Palmeira, E.M. Soil-Geosynthetic interaction: Modelling and analysis. Geotext. Geomembr. 2009, 27, 368-390. [CrossRef]

2. Moraci, N.; Cardile, G.; Gioffré, D.; Mandaglio, M.C.; Calvarano, L.S.; Carbone, L. Soil geosynthetic interaction: Design parameters from experimental and theoretical analysis. Transp. Infrastruct. Geotechnol. 2014, 2, 165-227. [CrossRef]

3. Lalarakotoson, S.; Villard, P.; Gourc, J.P. Shear strength characterization of geosynthetic interfaces on inclined planes. Geotech. Test. J. 1999, 22, 284-291.

4. Ramirez, R.R.; Gourc, J.P. Use of the inclined plane test in measuring geosynthetic interface friction relationship. Geosynth. Int. 2003, 10, 165-175. [CrossRef]

5. Pitanga, H.N.; Gourc, J.P.; Vilar, O.M. Interface shear strength of geosynthetics: Evaluation and analysis of inclined plane tests. Geotext. Geomembr. 2009, 27, 435-446. [CrossRef]

6. Carbone, L.; Gourc, J.P.; Carrubba, P.; Pavanello, P.; Moraci, N. Dry friction behaviour of a geosynthetic interface using inclined plane and shaking table tests. Geotext. Geomembr. 2015, 43, 293-306. [CrossRef]

7. Stark, T.D.; Poeppel, A.R. Landfill liner interface strengths from torsional ring shear tests. J. Geotech. Eng. 1994, 120, 597-615. [CrossRef]

8. Stark, T.D.; Williamson, T.A.; Eid, H.T. HDPE geomembrane/geotextile interface shear strength. J. Geotech. Eng. 1996, 122, 197-203. [CrossRef] 
9. Moss, A.; Anderson, L. Cylinder direct shear: A new test method. In Advances in Transportation and Geoenvironmental Systems Using Geosynthetics. In Proceedings of the Geo-Denver 2000, Denver, CO, USA, 5-8 August 2000; pp. 106-116.

10. ASTM D 5321-8. Determining the Coefficient of Soil and Geosynthetic or Geosynthetic and Geosynthetic Friction by the Direct Shear Method; ASTM International: West Conshohocken, PA, USA, 2008.

11. EN ISO 12957-1. Geosynthetics-Determination of Friction Characteristics_Part 1: Direct Shear Test; International Organization for Standardization: Geneva, Switzerland, 2018.

12. EN ISO 12957-2. Geosynthetics-Determination of Friction Characteristics_Part 2: Inclined Plane Test; International Organization for Standardization: Geneva, Switzerland, 2005.

13. Gourc, J.P.; Reyes-Ramirez, R. Dynamics-based interpretation of the interface friction test at the inclined plane. Geosynth. Int. 2004, 1, 439-454. [CrossRef]

14. Pavanello, P.; Carrubba, P.; Moraci, N. The characterisation of geosynthetic interface friction by means of the inclined plane test. Geotext. Geomembr. 2021, 49, 257-275. [CrossRef]

15. Briançon, L.; Girard, H.; Gourc, J.P. A new procedure for measuring geosynthetic friction with an inclined plane. Geotext. Geomembr. 2011, 29, 472-482. [CrossRef]

16. Carbone, L.; Pavanello, P.; Carrubba, P.; Briançon, L.; Scotto, M. Geosynthetic interface shear strength under static and seismic loading conditions. In Proceedings of the 10th International Conference on Geosynthetics, Berlin, Germany, 21-25 September 2014.

17. Wasti, Y.; Özdüzgün, Z.B. Geomembrane-Geotextile interface shear properties as determined by inclined board and direct shear box tests. Geotext. Geomembr. 2001, 19, 45-57. [CrossRef]

18. Ferreira, F.B.; Vieira, C.S.; Lopes, M.L. Soil-geosynthetic interface strength properties from inclined plane and direct shear tests-A comparative analysis. In Proceedings of the 6th Asian Regional Conference on Geosynthetics: Geosynthetics for Infrastructure Development, New Delhi, India, 8-11 November 2016; pp. 925-937.

19. Stoltz, G.; Nicaise, S.; Veylon, G.; Poulain, D. Determination of geomembrane-Protective geotextile friction angle: An insight into the shear rate effect. Geotext. Geomembr. 2019, 48, 176-189. [CrossRef]

20. Briançon, L.; Girard, H.; Poulain, D. Slope stability of lining systems-experimental modeling of friction at geosynthetic interfaces. Geotext. Geomembr. 2002, 20, 147-172. [CrossRef]

21. Palmeira, E.M.; Lima, N.R.J.; Mello, L.G.R. Interaction between soils and geosynthetic layers in large-scale ramp tests. Geosynth. Int. 2002, 9, 149-187. [CrossRef]

22. Pavanello, P.; Carrubba, P. Methodological aspects in the experimental measurement of the interface friction between geosynthetics. Procedia Eng. 2016, 158, 260-265. [CrossRef]

23. Pavanello, P.; Carrubba, P.; Moraci, N.; Pezzano, P. Some aspects concerning the laboratory evaluation of geosynthetic interface friction. In Proceedings of the 11th International Conference on Geosynthetics, Seoul, Korea, 16-21 September 2018; pp. 1344-1351.

24. Pitanga, H.N.; Vilar, O.M.; Gourc, J.P. Wear resistance of geosynthetic interfaces constituted by geomembranes and geospacers. Rev. Esc. Minas 2013, 66, 227-232. [CrossRef] 